\title{
Marxismo y humanismo
}

\author{
Marta Harnecker \\ Universidad de La Habana. Departamento de Sociología. \\ La Habana. Cuba
}

\section{Resumen}

La autora presenta una revisión crítica de la aportación de Althusser al marxismo, treinta anos después de la famosa revisión estructuralista del filósofo francés.

Palabras clave: Althusset, marxismo, antihumanismo, ideologia humanista.

\section{Abstract. Marxism and humanism}

The author presents a critical review of Althusser's work on marxism, thircy years after his famous contriburion to structural marxism.

Key words: Althusser, marxism, antihumanism, humanistic ideology.

\section{Sumario}

1. Campo ideológico en el que surge esta tesis

2. Lo que el antihumanismo teórico no niega contra sus detractores

3. La ruptura epistemologica: el hombre desaparece como concepto teótico
4. La adeterminación en última instancia»

S. El marxismo: donde el hombre desaparece como sujeto de la historia

6. Rechazo a pretensiones teóricas del hurnanismo, pero reconocimiento de su función práctica

Innumerables y prestigiosos. intelectuales de todas las latitudes han criticado a Louis Althusser por haber pretendido desterrar al hombre del marxismo. Se le ha acusado de reducirlo al papel de simple marioneta de estructuras, negando su papel en la historia. ¿Acaso su provocadora tesis del «antihumanismo teórico de Marx" ${ }^{1}$ no es la mejor prueba de ello?

1. Sobre esce tema los principales trabajos del autor son: "Marxismo y Humanismo", artículo aparecido en junio de 1964 en Cahiers de IISEA, publicado luego en la recopilación de artículos que conforman el libro Pour Marx, Maspéro, la edición, 1965, traducido al espa- 


\section{Campo ideológico en el que surge esta tesis}

Para entender lo que el filósofo francés quiso decir con estas palabras, usemos su propio método para analizar el pensamiento de un autor; examinemos primeramente un campo ideológico en el que surge esta tesis. Era la época del debate abierto, como consecuencia del XX Congreso del PCUS de febrero de 1956, sobre los problemas del socialismo y la crítica al culto a la personalidad.

Este congreso tuvo lugar en una época de euforia socialista. No sólo la "marea roja" se había expandido enormemente a nivel mundial, sino que la URSS, a pesar de los inmensos daños materiales sufridos por la guetra, había pasado a ser la segunda potencia económica y militar mundial. Y, además, según las declaraciones del PCUS, ya se habia logrado materializar la etapa del socialismo desarrollado, se entraba en la etapa de la construcción del comunismo. El Estado no era ya un Estado de clase, sino un Estado del pueblo entero. La Unión Soviética proclamaba la consigna: "Todo para el hombre, respeto a la legalidad y a la dignidad de la persona». Los partidos obreros celebraban las conquistas del humanismo socialista. Los intelectuales marxistas buscaban las garantías teóricas a estos temas en El capital, pero mucho más en las obras de la juventud de Marx. El tema de la alienación del hombre pasaba a ser uno de los temas centrales. Se hablaba de los problemas del hombre y se olvidaba la cuestión de la lucha de clases. Los filosofos de los países socialistas buscaban respuestas en los grandes pensadores cristianos contemporáneos: Maritain, Mounier, Teilhard de Chardin.

Althusser escribe su polémico artículo "Marxismo y humanismo" ocho años después del comienzo del «deshielo» iniciado por el XX Congreso, cuando la euforia había comenzado a declinar y el fracaso de la desestalinización oficial empezaba a causar profundo malestar entre los intelectuales. Se hacía cada vez más patente que las denuncias de Jruschov y el grupo gobernante pretendian que eel prólogo fuera - como dice Isaac Deutscher - también el epígono de la desestalinización» ${ }^{2}$. Al fin y al cabo el proceso habia sido iniciado por los propios colaboradores de Stalin, un ajuste de cuentas radical podía alcanzar-

fiol como La revolucion tébrica de Marx, Siglo XXI, 1967; Respuesta de Louis Aithusser a la polémica desatada en Ftancia a través de la revista La notvelle Critique, revista de! Partido Comunista Francés, escritas entre mayo del 65 y junio del 67 y reunidas en el libro Polemica sobre marxismo y humanismo, Siglo XXI, $1^{2}$ edición, 1968; Para una crítica de la práctica teórica (respuesta a John Lewis), libro que contiene los siguientes trabajos: "Respuesta a John Lewis de junio de 1972 w; "Observación sobre una categoria"; "Proceso sin sujeto ni fin(es)" de mayo de 1973 y "Sobre la critica al culto a la personalidad de mayo de 1972"; "Sobre el joven Marx", articulo escrito en julio de 1970 y publicado en Elementos de autocritica, Editoria! Laia, Barcelona, 1975; raducción de la edición ortiginal francesa de Librairte Hacherte, 1974; "Soutenance d'Amiens", de junio de 1975, publicada en La Pensée en octubre de ese afio e incluida luego en una recopilación de textos bajo el nombre de Positions, Ediciones Sociales, Parts, 1976, traducida al español como "Defensa de tesis de Amiens" en Posiciones, editorial Grijalbo. En este caso uso la edición francesa para las teferencias bibliográficas.

2. Deurscher, Isaac, La revolución inconclusa, México D.F: Era, 1976, p. 117. 
los. "Después de mostrar el enorme esqueleto escondido en el armario volvieron a cerrar la puertan ${ }^{3}$. En lugar de que las denuncias fueran el preludio de una clarificación de muchas cuestiones sobre los problemas de la construcción del socialismo, nada se hacía por romper la amnesia colectiva del pueblo soviético debida a décadas de falsifficación de la historia. Se denunciaban los hechos, no se investigaban sus causas.

El vacío analítico del pasado pretendía ser llenado por reflexiones sobre el humanismo socialista. Erich Fromm convoca, entonces, a varios intelectuales a realizar una obra que debía aparecer en Estados Unidos en torno a este tema. Un trabajo pedido a Althusser sobre el tema es rechazado porque su contenido es "contrario a la línea general del proyecto". El filosofo francés afirma que el debate, planteado en estos términos, no permite superar el dogmatismo preexistente, sino que se limita a incursionar en lo que denomina despectivamente: "las charlatanerías filosóficas "marxistas" sobre el hombre»".

¿Por qué atacar con tanta saf́a a quienes se preocupan honestamente por restaurar el carácter "humanista" del socialismo luego de los errores y horrores del período estalinista? ¿Por qué enunciar en ese contexto una tesis tan provocadora?

La razón es simple. Althusser constata la fuerza que han tomado las reflexiones sobre el humanismo en los medios intelectuales marxistas y ve con lucidez que si se marcha por ese camino se va a producir un bloqueo teórico que impedirá pasar del reconocimiento de los errores del período estalinista al conocimiento de sus causas. Lo que realmente está en juego es la posibilidad de resolver los problemas del socialismo. El autor está convencido que éstos no se podrán resolver si los intelectuales se dedican a reflexionar sobre el hombre, sólo podrán ser analizados y resueltos si se estudian las condiciones materiales de su surgimiento: las relaciones de producción en los países socialistas, la no correspondencia entre propiedad jurídica y apropiación real, entre estatización y grado de socialización de las fuerzas productivas, el problema de la división del trabajo que no es ajeno a los aparatos ideológicos del Estado, la relación entre partido único y Estado y sus consecuencias.

Según Althusser, el concepto de "culto a la personalidad" es un concepto ajeno a la teoría marxista y aunque éste denuncia prácticas, "abusos", "errores" y en ciertos casos "crímenes", nada explica sobre sus condiciones y sus causas. Lo más peligroso es que pretende explicar lo que en realidad no explica y, por lo tanto, no puede sino desviar las investigaciones de aquellos que pretenden esclarecer los hechos ${ }^{5}$. Y para explicar la acidez de sus críticas y el carácter provocador de su tesis sosriene: El palo estaba tan curvado hacia el lado del humanismo que era necesario curvarlo en sentido contrario, hacia el "antihumanismo" para que recobrase su posicion recta.

3. Op. cit, p. 118.

4. "Soutenance d'Amiens", op. cit, p. 149.

5. Nota sobre "La crítica al culro de la personalidad", en Para una crítica de La práctica tebrica (respuesta a John Lewis), op. cit., p. 88. 
Por lo demás, esta actirud no es excepcional. En todo debate teórico la ten" dencia es la de exagerar las tesis propias para desmarcarse de las tesis que se combaten. Sabemos que Marx y Engels no fueron ajenos a esta regla. Fue justamente ese énfasis en la producción material, contra el idealismo que dominaba el campo ideológico de su época, lo que motivó una lectura economicista, evolucionista del marxismo.

Es tal el impacto que produce en Althusser lo que ocurre teórica y políticamente entre los intelectuales marxistas en ese momento; es tan profundo el vacío teórico que constata, que abandona su proyecto inicial de hacer una gran tesis sobre la telación entre filosofía y política en el siglo XIX -recorrido que había estimado necesatio para la comprensión del pensamiento de Marx-y comienza a escribir sobre temas que permitan devolver al marxismo su carácter crítico y transformador.

\section{Lo que el antihumanismo teórico no niega contra sus detractores}

Pero antes de incursionar en el nudo de la tesis althusseriana nos parece importante adelantar, contra las acusacioncs tan profusamente vertidas, que su tesis del "antihumanismo teórico de Marx», en primer lugar, no niega que el objetivo del esfuerzo teótico y de la lucha política de Marx y de los marxistas sea la plena realización del hombre. Althusser, interpretando a Marx, aclara al comienzo de su artículo "Marxismo y humanismo" que "la lucha revolucionaria ha tenido siempre por objetivo el fin de la explotación y, por lo tanto, la liberación del hombre".

En segundo lugar, tampoco pone en duda que puedan existir concepciones humanistas del mundo que desempeñen un papel positivo en la lucha de clases y sirvan de motivación a los pueblos en su lucha por la liberación.

El pensador francés no desconoce, por ejemplo, el mérito histórico de las ideologías humanistas que alimentaron la lucha contra el feudalismo, contra la Iglesia, pero sostiene que no debe olvidarse que estas ideologias son inseparables de una clase burguesa en ascenso cuyas aspiraciones expresaban; al traducir a un nuevo lenguaje las exigencias de la economía mercantil y capitalista sancionada por el derecho mercantil burgués que corregía el antiguo derecho romano. "El hombre como sujeto, el hombre libre, sujeto de sus pensamientos es, ante todo, un hombre libre para poseer, para vender y comprar, un sujeto de derecho" ${ }^{7}$.

Pero, entonces, ¿cómo explicar las críticas que se hacen a Althusser sobre el rema del humanismo?

Pienso que, en parte, su origen puede estar en las expresiones excesivamenre radicales que el filósofo emplea para desmarcar su reflexión de la de los filósofos humanistas de su época, pero fundamentalmente, creo que esto se debe

6. "Marxismo y humanismo", en La revolución Tebrica de Marx, p. 182.

7. "Soutenance d'Amiens", op. cit., p. 176. 
a una lectura superficial e incompleta de sus escritos, por lo demás bastante hetméticos. Estimo que Althusser ha sido un gran incomprendido tanto en la época del esnobismo proalthusseriano como en el perfodo antialthusseriano que le siguió. Es interesante anotar que quienes acusan a Althusser de antihumanista sintomáticamente olvidan la palabra "teórico" que, en su tesis, adjetiva siempre el término "humanismon, y sin la cual es imposible comprender lo que éste autor plantea sobre este tema. Éste no habla de un "antihumanismo" a secas, sino de «antihumanismo téricon. Lo que su tesis pretende indicar es que "la categoria de hombre no desempeña en la obra de Marx papel teórico algunon. ${ }^{8}$.

Pero, ¿qué quiere significar Althusser cuando afirma que esta categoría no desempeña un papel teórico?

Para el filósofo francés una categoría desempería un papel teórico cuando forma parte de un todo solidario con otras categorías y no puede ser suprimida sin altetar el funcionamiento de ese conjunto. $Y$ en ese sentido, lo que merece, según él, el calificativo de "humanismo teóricon es la postura que contempla al hombre como centro del mundo en el sentido fillosófico del término, es decir, como esencia originaria y fin del mundo?.

Ahora bien, la tesis del antibumanismo teórico de Marx no puede separarse de otra de sus tesis: la que afirma que Marx ha producido una profunda revolución teórica inaugurando una nueva ciencia: la ciencia de la historia, susceptible de ser considerada como tal porque existe un determinado tipo de determinismo histórico que Marx expresa bajo la noción udeterminación en última instancia", y que la magnitud de este descubrimiento científico no puede entenderse si no se acepta la existencia de un corte o ruptura epistemologica entre el pensamiento del joven Marx, que representa su prehistoria ideológica, y el pensamiento del Marx maduro, fundador de la ciencia de la historia, en la que el hombre desaparece como sujeto del proceso histórico.

Analicemos brevemente estas tesis empezando por la ruptura epistemológica.

\section{La ruptura epistemológica: el hombre desaparece como concepto teórico}

Según Althusser, Marx no pudo llegar a su teoria cientifica sino realizando una crítica radical de la filosofía del hombre, que le sirvió de fundamento en los años de juventud.

En sus primeras obras podrfan distinguirse dos etapas. La primera, dominada por el humanismo racionalista liberal más cercano a Kant y Fichte que a Hegel (cuando combate la censura de prensa, las leyes feudales, el despotismo prusiano). En las obras de esta época Marx sostiene que el hombre está

8. Op. cit., p. 173.

9. Op. cir., p. 176. 
llamado a ser libre, que no es libre sino al ser razón y que la razón se encarna en el Estado. Por eso aboga por la libertad de prensa y considera al periodismo crítico como la esencia misma de la política. En aquel momento está convencido de que razones bien expuestas podrían llevar a un cambio de la sociedad. En una segunda etapa, Marx desilusionado - como todos los neohegelianos de su época-- frente a un Estado que permaneció sordo a la razón, se entusiasma con el humanismo de Feuerbach, que permite pensar la no-razón como enajenación y en esta enajenación la historia del hombre ${ }^{10}$.

Althusser sostiene, como es conocido, que Marx rompe con esta problemática humanista de la esencia genérica del hombre y de la alienación en 1845 , en la Ideologia Alemana, y que esta ruptura con toda teoría que funda la historia y la política en la esencia del hombre marca de manera radical la evolución de su pensamiento. Más tarde matizará esta afirmación diciendo que en 1845 "algo comienza" que es irreversible, pero que se trata de una "ruptura continuan; el comienzo de un largo trabajo.

La nueva ciencia de la historia evidentemente no surge "armada por entero en la cabeza de Marx» en 1845. En ese momento sólo comienza a construirse y cuando esto ocurre no está libre de todo su pasado - de toda la prehistoria ideológica y filosofica de la que surge-11. Nadie puede sorprenderse, entonces, que en esos ańtos Marx utilice nociones ideológicas o categorías filosóficas de las que más tarde se desembarazará. Esta ruptura teórica - que sólo es posible porque Marx logra desplazarse a posiciones de clase absolutamentc inéditas, a posiciones de clase proletarias- ${ }^{12}$ se refleja en tres aspectos indisociables: primero, en la formación de una teoría de la historia y de la política fundada en conceptos radicalmente nuevos: modo de producción, fuerzas productivas, relaciones de producción, formación social, infraestructura, superestructura, ideología, clases, lucha de clases, etc. ${ }^{13}$; segundo, en la critica radical de las pretensiones teóticas de todo humanismo filosófico, y tercero, en la definición del humanismo como ideologia ${ }^{14}$.

"El antihumanismo teórico de Marx va mucho más allá de un simple arreglo de cuentas con Feuerbach: cuestiona también las filosofias de la sociedad y de la historia existentes y la tradición filosófica clásica, $y$, por lo tanto, a través de ellas toda la ideología burguesan ${ }^{15}$. Althusser sostiene que la categoría de hom-

10. "Marxismo y humanismo", en Polémica sobre marxismo y hamanismo, p. 9.

11. "Respuesta a John Lewis", en Para una critica de la práctica tebrica (respuesta a John Lewis), op. cit., p. 57.

12. Althusser corrige aquil sus primeros escritos sosteniendo que es la revolución filosbfica la que domina la arupturan cientifica. Veamos: al karreglar cuentas con su filosofia anterion en 1845, "Marx ha abandonado sus posiciones teóricas de clase burguesa liberal y pequefoburguesa revolucionaria, para adoptar nuevas posiciones teóricas de clase, revolucionariasproletatias; es por eso que pudo plantear las bases de la teoría cientifica de la historia como historia de la lucha de clases", op. cit., p. 61.

13. "Sobre la evolucion def joven Marx", Elementos de autocritica, op. cit., p. 75 .

14. "Marxismo y humanismo", op. cit., p. 12.

15. "Soutenance d'Amiens", op. cit., p. 177-178. 
bre no aparece ni en los textos nucleares de la filosofía marxista, ni en su teoria de las formaciones sociales y de la historia. Lo que está en discusión no es el humanismo en general, es la pretensión teórica de una concepción humanista que pretende explicar la sociedad y la historia partiendo de la esencia humana, del sujeto humano libre, del sujeto de la acción moral y polírica. El filósofo francés sostiene que Marx sólo pudo fundar la ciencia de la historia y escribir El capital porque rompió con la pretensión teórica de todo humanismo.

"En El capital Marx muestra que lo que determina en última instancia una formación social y nos hace conocerla no es el fantasma de la esencia o de la naturaleza humana, no es el hombre, ni incluso "los hombres", sino una relación, la relación de producción, que conforma la base, la infraestructura» ${ }^{16}$. Las relaciones sociales de producción no pueden ser consideradas solamente como relaciones humanas, relaciones entre hombres. Son relaciones entre agentes de la producción, es decir, entre hombres que tienen una función bien determinada en la producción de bienes materiales. La relación entre ellos depende de la forma en que ellos se relacionan con los medios de producción, si son propietarios de los medios de producción o productores directos. Esta relación entre los hombres pasa, por lo tanto, a través de una relación con los objetos: los medios de producción. Una de las mayores mistificaciones teóricas que puede darse es pensar que las relaciones sociales son relaciones en las que sólo intervienen los hombres cuando también intervienen las cosas, los medios de producción extraídos de la naturaleza material. Marx considera a los hombres como "portadores" de una función en el proceso de producción. La actuación de los hombres está determinada por las relaciones de producción.

\section{La "determinación en última instancia"}

Algunos han creído ver una contradicción interna entre la concepción marxista del proceso histórico como un proceso de desarrollo sujeto a leyes, es decir, a un determinado tipo de determinismo y la importancia que el marxismo atribuye a la lucha de clases, es decir, a la acción de los hombres en la historia. Si se tratara del mismo determinismo económico que rige en los procesos de la naturaleza, La contradicción sería flagrante, pero no se trata de eso. Para dar cuenta de la especificidad del determinismo que rige el proceso histórico, Marx usa el término de "determinación en última instancia». Althusser opina que esta expresión, a pesar de su aspecto inocuo, "transforma de arriba abajo las precedentes concepciones dominantes de la sociedad y de la historia".

Para poder explicar cómo concibe este determinismo, Marx considera a la sociedad bajo la metáfora de un edifico, es decir, adopta la forma de un dispositivo espacial que asigna determinadas ubicaciones en el espacio a las diferentes realidades ${ }^{17}$. La base del edificio o infraestructura está constituida por la 
estructura económica o conjunto de relaciones de producción. Sobre ella se erige la superestructura jurídico-política e ideológica, que se encuentra determinada "en última instancia» por la infraestructura. Si se trata de una "últiman instancia, tiene que haber otras que también determinen. Por eso Althusser considera que este señalamiento de Marx desempeña un doble papel: por un lado, diferencia radicalmente a Marx de toda postura mecanicista y, por otro, uintroduce en la determinación un abanico de diferentes instancias, to que supone que la sociedad es un todo diferenciado, complejo y articulado, donde la última instancia ${ }^{18}$ fija los límites reales de las demás ${ }^{19}$, su autonomía relativa y la forma de actuar sobre la propia base, así como la eficacia de dicha acción ${ }^{20}$.

Afirmar que la infraestructura es el factor determinante en tíltima instancia equivale a diferenciarse de todas las filosofias idealistas de la historia y adoptar una posición materialista. Pero al indicar que se trata sólo de una determinación en última instancia, equivale a diferenciarse de todo determinismo mecanicista y a adoptar una posición dialéctica. Althusser advierte que la dialéctica marxista nada tiene que ver con la dialéctica hegeliana, ya que Marx ucoloca la dialéctica ante sus condiciones reales de ejercicio, la protege de la locura especulativa, le prescribe la obligación de ser materialista, es decir, de reconocer que sus propias formas vienen prescritas por la materialidad de sus condiciones" 2 ?

Pero Marx sólo se limita a señalar a partir de dónde hay que reflexionar acerca de la causalidad propia de la ciencia de la historia, no existe en su obra un desarrollo teórico acerca de este nuevo tipo de determinismo. Pensamos que para profundizar en él habría que hacer un estudio acerca del carácter tendencial de las leyes que rigen el modo de producción capitalista y acerca del papel que desempeña la lucha de clases en las tendencias que contrarrestan estas leyes. Recordemos sus formulaciones sobre la baja tendencial de la tasa de ganancia.

Durante mucho tiempo, tanto intelectuales como dirigentes políticos olvidaron la especificidad del determinismo marxista y cayeron en una interpretación evolucionista de los hechos históricos, más cercana a la causalidad mecánica de las ciencias naturales que al nuevo tipo de la causalidad descubierta por Marx. De ahf la interpretación evolucionista de la crisis que vivía el mundo capitalista, que preanunciaba su hecatombe final. No podemos negar que hay textos de los clásicos del marxismo que se prestan para dicha interpretación, uno de ellos es el de Lenin acerca del imperialismo concebido como fase final del capitalismo. De ah́ también la importancia de aquellos pensadores que supieron insistir en que la crisis estructural del capitalismo no conduce necesariamente a la revolución, sino que puede tener dos salidas: una

18. Económica.

19. Jurídico-politica e ideológica.

20. Op. cit., p. 153.

21. Op. cit., p. 154. 
salida reformista de recomposición del sisterna y otra revolucionaria, que busca destruir el viejo sistema e inaugurar uno nuevo.

\section{El marxismo: donde el hombre desaparece como sujeto de la historia}

Pasemos ahora a examinar la tesis de Althusser, acerca de la historia como proceso sin sujeto.

Marx sostiene en El Dieciocho Brumario de Luis Bonaparte"2: "Los hombres hacen su propia historia, pero no la hacen a su libre arbitrio, bajo circunstancias elegidas por ellos mismos, sino bajo aquellas circunstancias con las que se encuentran directamente, que existen y les han sido legadas por el pasadon. No es sino esto lo que Althusser quiere expresar en su controvertida tesis sobre el "proceso sin Sujeto".

El autor considera que como los individuos humanos actúan en y bajo las determinaciones de las formas de existencia histórica de las relaciones sociales de producción y reproducción, no pueden ser considerados "sujetos "libres" y "constituyentes", en el sentido filosófico de esos términos" $23 . \mathrm{Y}$ al no poder serlo no pueden ser considerados, filosóficamente hablando, el Sujeto de la historia. Los hombres son sujetos en la historia y no de la historia, es decir, no son los exclusivos artífices de la historia. La historia no depende de su exclusiva voluntad, pero actúan realmente en la historia y, dependiendo de su acción, ésta puede tomar un rumbo u otro.

Según Lenin no existe conflicto entre la necesidad histórica y la importancia del individuo. Y tampoco la idea de la necesidad histórica menoscaba en nada el papel del individuo en la historia, porque toda la historia se compone precisamente de acciones de individuos que son indudablemente personalidades. El problema real que surge al valorar la actuación social del individuo consiste en saber en qué condiciones se asegura el éxito a esta actuación; en determinar dónde está la garantía de que esa actividad no resulte en un acto individual que se hunda en el mar de actos opuestos ${ }^{24}$. El manxismo no excluye el combate, por el contrario ayuda a encontrar el lugar donde es más eficaz el combate para transformar el mundo. "Pero ese lugar - dice Althusser- no es un punto y no es algo fijo, es un sistema articulado de posiciones comandadas por la determinación en última instancia ${ }^{25}$.

El filósofo francés sostiene que la filosofía burguesa se ha apoderado de la noción de sujeto con fines ideológicos precisos, para transformarla en su categoría filosófica número uno; para plantear la cuestión del Sujeto del conocimiento, del Sujeto de la moral y del Sujeto de la historia. Marx, por el contrario, no concibe la historia real como susceptible de ser reducida a un Origen, una

22. K. MARX, El Dieciocho Brumario de Luis Bonaparte, en Marx-Engels, Obras escogidas, t. 1, p. 408.

23. Ibidem.

24. LENIN, Quienes son los «amigos del pueblo», Obras Completas, Edición Cartago, t. 1, p. 170.

25. "Soutenance d'Amiens", op. cit, p. 160. 
Esencia, o una Causa que sería su Sujeto identificable y responsable, capaz, por lo tanto, de rendir cuentas de todo lo que ocurre en la historia.

Al proponer la radical tesis de "proceso sin Sujeto", Althusser pretende trazar una "línea de demarcación" entre las posiciones materialistas dialécticas y las posiciones idealistas burguesas y pequeñoburguesas ${ }^{26}$. La historia, como dice Althusser, "no tiene, en el sentido filosófico del término, un Sujeto, sino un motor: la lucha de clases" ${ }^{27}$. No es el hombre o los hombres en general los que hacen la historia, sino las masas, es decir, las fuerzas sociales comprometidas en la lucha de clases. Por no comprender el verdadero sentido de la teoría marxista de la historia y del papel que en ella desempeña la lucha de clases se cae frecuentemente en dos errores que son funestos para el movimiento revolucionario: el economismo o espontaneísmo, que predica la sumision a las leyes del desarrollo económico, y el voluntarismo, que desconoce las condiciones objetivas mínimas necesarias para emprender una acción revolucionaria victoriosa.

\section{Rechazo a pretensiones teóricas del humanismo, pero reconocimiento de su función práctica}

Por último, Althusser no pretende negar, como algunos de sus críticos lo pretenden, que la preocupación por el hombre haya estado en el centro de la obra de Marx, antes y desputés de la ruptura, lo que él señala es que en las obras del joven Marx esta preocupación estaba acompañada por un esfuerzo por pensar los problemas del hombre con categorías humanistas y, en sus obras maduras, estas categorías desaparecen y nuevas categorías, muy diferentes a las anteriores, ocupan su lugar.

Lo que Althusser cuestiona entonces, en sintesis, es el valor teórico del concepto, no la tealidad seńalada por éste, $\mathrm{ni}$, por lo tanto, la necesidad de la existencia de ideologias humanistas, ya que éstas pueden desempeñar una función ideológica práctica muy importante. Él ve claro que la sinrazón y la inhumanidad histórica que pesan sobre el pasado de la URSS: el terror, la represión, el dogmatismo - que se hacen patentes en el XX Congreso del PCUS- es lo que explica la avalancha de reflexiones sobre el humanismo en los países socialistas y entre los intelectuales marxistas de aquel momento ${ }^{28}$. El pensador francés no desconoce la importancia de las denuncias contenidas en estos discursos, les atribuye una importancia práctica. Ellas ponen el dedo en la llaga, pero no sanan la herida.

El término humanismo sirve para señalar un conjunto de realidades, un conjunto de errores cometidos por los países socialistas, pero, volvemos a insistir, no nos da los medios para conocerlos. Nos permite reconocer los errores, pero no conocer sus causas, y, por lo tanto, nos impide rectificarlos. No hay terapéutica

26. "Proceso sin sujeto ni fin(es)", op. cit, p. 80.

27. Op. cit, p. 80-81.

28. "Matxismo y humanismo", op. cit., p. 28. 
histórica de los errores si nos quedamos en los síntomas de la enfermedad y no vamos a su causa. Para poder resolver los problemas planteados por la ausencia de un humanismo práctico en los países socialistas, no basta hablar del hombre, es necesario ir a buscar lo que determina ese efecto de deshumanización en un sistema social cuyo objetivo final, el planteado por Marx, era el pleno desarrollo de los individuos respetando sus diferencias, es decir, su individualidad.

No está de más decir aquí que todo colectivismo que anula la individualidad, es decir, los rasgos diferenciados de cada miembro de la sociedad, es una flagrante deformación del marxismo. Basta recordar que Maxx criticaba el derecho burgués por pretender igualar artificialmente a los hombres en lugar de reconocer sus diferencias y por eso sostenía que una distribución verdadetamente justa tenía que tener en cuenta las necesidades diferenciadas de los hombres. De ahr su máxima: "De cada cual según su trabajo a cada cual según sus necesidades".

El recurso a la ideologia humanista, que Althusser critica no se debe a que el autor desconozca la importancia de las preocupaciones subyacentes a estas reflexiones, sino a que este recurso a la ideología substituye el recurso a la teorfa, y nos deja sin armas teóricas para resolver realmente los problemas. "Sería un error - afirma el filósofo- elaborar una teoría de la individualidad que prescinda de los efectos de la estructura social sobre el individuon, de ahí su rechazo a reducir todo lo ocurrido en la URSS y, en general, en los paises socialistas, al culto a la personalidad.

Es necesario hacer una teoría, agrega, ude las formas de existencia de la individualidad, partiendo de las estructuras existentes del modo de producción existente: es la única vía para todo lo que concierne a los efectos sobre la individualidad actual de las estructuras existentes". Es necesario, por lo tanto, invertir la cuestión y la mayor parte de los problemas que tienen sentido encontrarán su solución al ser planteados en función de los efectos de la estructura social. "La terapéutica histórica de estos efectos estructuralcs sobre el individuo se anunciará entonces en términos de transformación o creación de las estructuras indispensables para la solución de estos problemas: estructuras de la existencia económica, política, cultural, individual, etcétera». Y aclara finalmente que evidentemente este método sólo puede tocar las cuestiones que pertenecen a su terreno, no las otras. Para las cuestiones que quedarán por ser solucionadas será necesario buscar por el lado del psicoanálisis y por el lado de aquello que se llegará a constituir algún día: una teoría a las prácticas ideológicas, como el arte, la religión, etcétera ${ }^{29}$.

Han pasado ya treinta y dos años desde aquellos trabajos iniciales del filósofo francés que tantas críticas despertaron, ¿y qué ha ocurrido en la producción teórica de los intelectuales marxistas? ¿Cuál es el instrumental teórico con el que hoy contamos para poder analizar la crisis y el derrumbe del socialismo? ¿Qué análisis riguroso existe en la actualidad respecto a la forma actual 
que ha adoptado el modo de producción capitalista? ¿Dónde están los proyectos alternativos al neoliberalismo en los páses del primer mundo y del ter. cer mundo? ¿Cómo hacer para que el socialismo "democrático" que no es sino la versión actual del "socialismo humanista" o "socialismo con rostro humano" de la década de los sesenta, logre encarnarse en un proyecto alternativo concreto y no en meras generalidades, por muy nobles que éstas sean, como el respeto a los derechos humanos?

Para terminar quisiera hacer una proposición: que Cuba se convierta en el país convocante para configurar una agenda de los principales temas a elaborar para poner la ciencia de la historia fundada por Marx a la altura de nuestros tiempos y así armar ideológicamente a nuestros pueblos para el combate por un mundo mejor, en el que el hombre no sea el lobo del hombre, sino su hermano. 